\title{
A EVOLUÇÃO DA JURISPRUDÊNCIA TRABALHISTA QUANTO AO TRATAMENTO DADO AO TRABALHO ESCRAVO E A REALIDADE NO BRASIL ${ }^{1}$
}

THE EVOLUTION OF LABOR JURISPRUDENCE REGARDING THE TREATMENT OF SLAVE LABOR AND THE REALITY IN BRAZIL

Ana Rita Patrezi ZANATTA²

Maria Claudia Santana Lima de OLIVEIRA ${ }^{3}$

ISSUE DOI: 10.21207/2675-0104.2018.731

\section{RESUMO}

O combate constante às práticas de trabalho escravo contemporâneo é necessário na medida em que o crime sempre foi um problema presente na realidade nacional. Quanto à órbita jurídica, o mesmo encontra-se tipificado no artigo 149 do Código Penal Brasileiro, alterado pela lei 10. 803/2003, definindo-o como "submeter a trabalhos forçados ou a jornada exaustiva, sujeitar a condições degradantes de trabalho e restringir, por qualquer meio, sua locomoção em razão de dívida contraída com o empregador ou preposto". Destarte, o objetivo principal da pesquisa é, por meio da avaliação do comportamento da lei e da jurisprudência trabalhista a respeito, buscar os motivos da realidade não se

\footnotetext{
${ }^{1} \mathrm{O}$ presente artigo sintetiza a monografia de conclusão da pesquisa, realizada para o Programa Interno de Bolsas de Iniciação Científica (PIBIC 2017-2018) da Faculdade de Direito de Franca (FDF), Franca/SP.

${ }^{2}$ Discente da Faculdade de Direito de Franca (FDF), Franca/SP. Bolsista do Programa Interno de Bolsas de Iniciação Cientítica (PIBIC 2017-2018).

${ }^{3}$ Possui graduação em Direito pela Faculdade de Direito de Franca (1986) e mestrado em Direito pela Universidade de Franca (2002). Atualmente é professora titular da cadeira do Direito do Trabalho, no período noturno, da Faculdade de Direito de Franca. Tem experiência na área de Direito, com ênfase em Direito do Trabalho.
} 
encontrar em concomitância com a letra da lei, visto que apresenta melhoras seguidas rapidamente de pioras quanto ao número de escravizados.

Palavras-chave: Trabalho escravo contemporâneo. Órbita jurídica. Jurisprudência.

\section{ABSTRACT}

The constant combat of contemporary slave labor practices is necessary as crime has always been a problem present in our national reality. Regarding the legal orbit, this is typified in Article 149 of the Brazilian Penal Code, amended by Law 10803/2003, defining it as "submitting to forced or full-time work, subjecting to degrading conditions of work and restraining, by any means, their locomotion by reason of debt contracted with the employer or representative. Therefore, the main objective of the research is, through the evaluation of the behavior of the law and labor jurisprudence in this regard, to seek the motives of reality not to be in concomitance with the law, since it presents improvements followed quickly of worsening to the number of enslaved.

Keywords: Contemporary slave labor. Legal orbit. Jurisprudence.

\section{INTRODUÇÃO}

Para que se entenda o Direito do Trabalho, é necessário compreender como o trabalho foi tratado com o decorrer da história, enquadrando o mesmo com o contexto tratado. Ele, nos primórdios dos tempos e em sociedades de ampla relevância, como Grécia e Roma, foi frequentemente colocado como sinônimo de desonra e indignidade, e isso por conta de ser relacionado e dirigido àqueles considerados com menor prestígio social e, portanto, tratados como escravos. Por conseguinte, a primeira maneira de trabalhar foi a de escravidão, incorporada como fator cultural comum de diversas comunidades e considerado amplamente justificável. ${ }^{4}$

Segadas Vianna ${ }^{5}$, no livro Instituições de Direito do Trabalho, dá ênfase ao trabalho escravo como precursor do Direito Trabalhista, avaliando a situação atual de forma comparada aos antecedentes históricos. Cita o surgimento do trabalho escravo, através de combates entre grupos, nos quais os vencedores, após perceber ser mais cômodo escravizar seus inimigos do que matá-los, subordinavam os perdedores a trabalhos forcados. E desde então a escravidão foi considerada justa e necessária, e até mesmo pensadores importantes chegaram a justificá-la, sob o fundamento de que para que um homem pudesse praticar sua racionalidade e conseguir cultura, era necessário de que fosse rico e ocioso, precisando,

\footnotetext{
${ }^{4}$ MARTINS, Sérgio Pinto. Direito do Trabalho. 33 Edição, São Paulo-SP, Editora Saraiva, 2017.

${ }^{5}$ SUSSEKIND, Arnaldo. VIANA, Segadas. MARANHÃO, Délio. Instituições do direito do trabalho. 15 Edição, São Paulo-SP, Editora LTr.
} 
assim, de escravos para prática de atividades braçais e, portanto, desonrosas.

Com relação ao Brasil, a escravidão foi amplamente explorada. Primeiramente, escravizaram-se os índios. Devido ao repúdio da Igreja, passou-se a escravizar os negros, que eram sequestrados da África e trazidos ao Brasil para prática de trabalho braçal. E foi por meio desse trabalho desumano ao qual se submeteu o negro que o Brasil colonial se situou em uma situação de considerável conforto. ${ }^{6}$

Contudo, com a Revolução Francesa de 1789, veio um dever de grande importância do Estado: o de dar meios de sobrevivência ao trabalhador que se encontrasse desempregado. Portanto, eis que surge o primeiro direito de ordem social e, também, econômica: o direito de trabalhar. Surge, então, o Direito do Trabalho, juntamente com o contrato de trabalho. ${ }^{7}$

Em relação ao seu surgimento, Segadas Vianna coloca a Revolução Industrial como causadora dessa criação. Fala da mesma juntamente com a Revolução Política. Enquanto que a segunda tornava o "cidadão como categoria racional na ordenação política da sociedade", a primeira colocava a liberdade humana como mera teoria, visto a dependência do homem perante a indústria. ${ }^{8}$ Nos dizeres de Ripert, "a experiência demonstra que a liberdade não basta para assegurar a igualdade, pois os mais fortes depressa se tornam opressores". ${ }^{9} \mathrm{Nas}$ palavras de Palacios, "A liberdade sem freios será a causa da brutalidade e da usurpação se há desigualdade nas forças individuais."

A partir de então, diversas normas surgem com o intuito de proteção ao trabalhador: em 1919, o Tratado de Versalhes, em que criou a Organização Internacional do Trabalho. Direitos trabalhistas que passaram a ser constitucionalizados, sendo a Constituição do México a primeira a tratar sobre. Após o holocausto e a Segunda Guerra Mundial, direitos trabalhistas passaram a ser discutidos com maior frequência. A Declaração Universal dos Direitos Humanos, de 1948, prevê alguns, como repouso, lazer, férias remuneradas etc. ${ }^{11}$

No Brasil, as primeiras constituições não trataram a cerca de Direito do Trabalho. Porém, trouxe a legislação ordinária certos direitos de ordem social: leis que falavam sobre trabalho de menores (1891), a lei do ventre livre (1871) e a lei áurea, em 1888. Em 1930, o Ministério do Trabalho foi criado. Mas foi apenas em 1934 que direitos trabalhistas passaram a ser tratados de maneira efetiva e expressa

\footnotetext{
${ }^{6}$ SUSSEKIND, Arnaldo. VIANA, Segadas. MARANHÃO, Délio. Instituições do direito do trabalho. 15 Edição, São Paulo-SP, Editora LTr.

${ }^{7}$ MARTINS, Sérgio Pinto. Direito do Trabalho. 33 Edição, São Paulo-SP, Editora Saraiva, 2017.

${ }^{8}$ SUSSEKIND, Arnaldo. VIANA, Segadas. MARANHÃO, Délio. Instituições do direito do trabalho. 15 Edição, São Paulo-SP, Editora LTr.

${ }^{9}$ Idem.

${ }^{10}$ Idem.

${ }^{11}$ MARTINS, Sérgio Pinto. Direito do Trabalho. 33 Edição, São Paulo-SP, Editora Saraiva, 2017.
} 
por meio de uma Constituição Federal, instituída durante o governo de Getúlio Vargas. ${ }^{12}$

Criou-se a Consolidação das Leis do Trabalho, que não se trata de um código, mas sim da maneira encontrada de reunir e proteger as leis de caráter trabalhista no Brasil. ${ }^{13}$

A CLT teve grande influência na formação da constituição de 1946, considerada a mais democrática até ali. O direito de greve passou a ser constitucionalmente reconhecido, e diversos direitos foram garantidos aos trabalhadores, rompendo com o corporativismo estabelecido pela Constituição de 1937. ${ }^{14}$

Em contrapartida, o liberalismo econômico de Adam Smith pouco favoreceu o trabalhador, ressaltando a necessidade de criar-se um direito do trabalho. E isso devido à ampliação das diferenças entre empregado e empregador promovida pelo livre mercado, e a exacerbada e constante busca pelo lucro em detrimento de uma classe social amplamente abusada. ${ }^{15}$

Esses abusos levaram a primeiras leis pouco vantajosas ao trabalhador, se comparadas às posteriores. Como exemplo disso, tem a Lei de Amparo aos Pobres, uma das primeiras a serem criadas na Inglaterra: as obrigações do Estado e da Igreja eram amplamente confundidas com a lei e os filhos de indigentes tinham de trabalhar para garantir alimentação. Isso revela o quão ligado ao trabalho escravo estão as primeiras leis de caráter trabalhista: mesmo que com o intuito de proteger o trabalhador, a conhecida legislação industrial tinha uma certa característica de subordinar indivíduos, tornando-os dependentes de atividades precárias para que sobrevivessem.

A Lei de Amparo aos Pobres, todavia, se mostrou favorável ao intervencionismo estatal humanista. E, quanto a isso, a interferência do Estado nas relações trabalhistas trouxe benefícios atrelados a malefícios. Partindo do pressuposto de que "o direito do trabalho nasceu também e paralelamente como expressão do intervencionismo do Estado". ${ }^{16}$, mostrou-se necessário o estudo a respeito dessa intervenção. O intervencionismo humanista se revelou por meio de técnicas neoliberais do Estado, em que regulava o setor trabalhista na medida em que se revelava

\footnotetext{
${ }^{12}$ Idem.

${ }^{13}$ MARTINS, Sérgio Pinto. Direito do Trabalho. 33 Edição, São Paulo-SP, Editora Saraiva, 2017.

${ }^{14}$ MARTINS, Sérgio Pinto. Direito do Trabalho. 33 Edição, São Paulo-SP, Editora Saraiva, 2017.

${ }^{15}$ NASCIMENTO, Amauri Mascaro. Curso de Direito do Trabalho. 29 Edição, São Paulo-SP, Editora Saraiva, 2014.

${ }^{16}$ NASCIMENTO, Amauri Mascaro. Curso de Direito do Trabalho. 29 Edição, São Paulo-SP, Editora Saraiva, 2014.
} 
necessário, como na formulação de contratos. Todavia, o intervencionismo estatal se revelou também por meio de ditaduras, como o fascismo e o nazismo, mostrando-se prejudicial ao direito do trabalho e ao trabalhador.

O capítulo buscou demonstrar a relação entre como o trabalho sempre foi visto- atividade indigna, desonrosa- e a perseverança do trabalho escravo nos dias atuais, ao passo que trouxe a evolução do Direito Trabalhista: o surgimento e desenvolvimento do Direito do Trabalho funcionou como uma resposta a essa subordinação exacerbada que chegou a ameaçar a condição de existência de diversos seres humanos.

Em relação ao capítulo 2, Princípios do Direito do Trabalho, o Direito do Trabalho, como demonstrado, necessita de uma estrutura para em que possa se apoiar, como meio de suprir lacunas ou conceitos decorrentes do seu campo de atuação. Destarte, é fundamental a presença de princípios de ordem trabalhista capazes de completar a matéria de maneira concreta e, de certa forma permanente. Conforme Galantino ${ }^{17}$ comparados com as leis, os princípios apresentam caráter mais duradouro, podendo ser caracterizados como fontes mais seguras, já que as leis tendem a se modificar mais facilmente diante de mudanças no meio social.

O Princípio de Proteção, visto que busca por meio de uma desigualdade formal assegurar uma igualdade real, permite com que abusos cometidos no passado, como a suposta liberdade de feitura de contratos, permitida por diversos países e causadora de inumeráveis formas de beneficiamento do empregador em detrimento de sofrimento alheio, possam ser evitados mediante o apoio dado ao trabalhador, que se encontra em constante situação de desamparo. É a própria razão de ser do Direito Trabalhista, visto que, sem ele, não haveria o que se dizer em ambiente de trabalho, mas sim em ambiente de abusos e de condições degradantes, fazendo com que deixasse de fazer sentido. ${ }^{18}$ Assim, o princípio serve de fundamentação para diversas jurisprudências trabalhistas, como, por exemplo, em se tratando de pagamento por danos morais coletivos.

Portanto, reduzir a importância do princípio de proteção pode trazer consequências irreversíveis ao meio social, regredindo, por exemplo, em relação à própria conceituação de trabalho escravo, podendo gerar consequências irreversíveis no tratamento dado ao mesmo.

\footnotetext{
${ }^{17}$ Citado na obra de Américo Pla Rodriguez, Princípios de Direito do Trabalho. 3 Edição, São PauloSP, Editora Ltr.

${ }^{18}$ RODRIGUEZ, Américo Pla. Princípios de Direito do Trabalho. 3 Edição, São Paulo-SP, Editora LTr.
} 
O princípio da continuidade reza que, ao estabelecer um contrato, as partes tem o dever de continuá-lo, ou seja, deverão cumprir o que estabeleceram, visto que um contrato não se esgota com a realização de apenas alguns de seus termos. Mediante a característica de submeter indivíduos a força contratual e da resistência em admitir rescisões unilaterais, houve certo receio quanto a possibilidade de, ao se encontrar em condição de desemprego, principalmente em épocas de crise, o empregado se submeter a condições deploráveis de trabalho e se tornar absolutamente subordinado as cláusulas contratuais, trazendo uma tendência ao emprego de condições análogas a de escravo e privação da liberdade de ir e vir. ${ }^{19}$

O desejo por segurança e proteção, em tempos de crises econômicas e políticas e, portanto, de aumento de desemprego, pode levar a aceitação de condições de emprego desrespeitadoras da dignidade da pessoa humana. É comum, no meio social, trabalhadores terem maior receio de perder o emprego do que de trabalharem como escravos, conforme o autor brasileiro Meton. ${ }^{20}$ Por conseguinte, o aumento do número de trabalhadores em condições de trabalho escravo é comum em épocas de crises econômicas, visto que estão acompanhadas do desejo de estabilidade por parte do indivíduo que se encontra desempregado.

O Princípio da Primazia da Realidade prega que, havendo contradição entre o convencionado em contrato e a realidade dos fatos, a segunda deve prevalecer, como meio de garantir a predominância do que ocorre na prática. Esse desencontro entre realidade e convenção contratual pode ser devido a diversos fatores, como decorrente de um erro, da falta de cumprimento de pressupostos formais, da falta de atualização e, também, do intuito direcionado a simulação de um contrato de trabalho. Essa simulação pode ser total, quando se simula a respeito de um contrato que, na verdade, não existe; como também parcial, cujo contrato de trabalho apresenta-se de uma maneira, sendo que na verdade versa de outra. Nesse caso, a simulação pode ser exercida tanto por ambas as partes e, desse modo, bilateralmente; como por apenas uma, de maneira imposta, utilizando-se de coerção para que aconteça. ${ }^{21}$ Quanto à última, pode dar

\footnotetext{
${ }^{19}$ RODRIGUEZ, Américo Pla. Princípios de Direito do Trabalho. 3 Edição, São Paulo-SP, Editora LTr.

${ }^{20}$ Citado na obra de Américo Pla Rodriguez, Princípios de Direito do Trabalho. 3 Edição, São PauloSP, Editora Ltr.

${ }^{21}$ RODRIGUEZ, Américo Pla. Princípios de Direito do Trabalho. 3 Edição, São Paulo-SP, Editora LTr.
} 
causa ao trabalho escravo contemporâneo. Graças a tal princípio, o trabalho escravo pode ser tratado e, consequentemente, combatido da forma jurídica que verificamos nos dias atuais, sendo reprimido mesmo em situações em que é disfarçado.

O princípio da Razoabilidade, aplicado ao Direito do Trabalho, permite com que, através da razão, o homem possa distinguir uma situação real de uma simulação. Ou seja, busca medir e compreender a verossimilhança entre soluções, de modo a diferenciar uma relação comum de uma relação trabalhista, e a última de qualquer forma de farsa. ${ }^{22}$

Esse princípio, todavia, conforme Americo Plá Rodriguez ${ }^{23}$, possui a tendência para a terceirização, devido ao seu impulso flexibilizador.

O Princípio da boa-fé, por sua vez, sempre esteve presente na jurisprudência trabalhista e, ao rever seus conteúdos, algumas conclusões podem ser feitas: a boa-fé é sempre exigida de ambas as partes na relação trabalhista. Nesse sentido, afirma o ex-juiz do trabalho Dr. Pereira Manelli: "Se em matéria trabalhista o princípio da boa-fé adquire uma importância essencial para a subsistência do vínculo entre as partes, deve-se convir que toda atitude que se afasta dos conceitos de 'bom trabalhador' e de 'bom empregador' envolve responsabilidades". ${ }^{24}$

O Princípio de Igualdade e o de Não Discriminação foram tratados juntamente visto que completam-se entre si.

O Princípio de Igualdade, juntamente com o Princípio de Não Discriminação, objetiva a manutenção da dignidade da pessoa humana, a preservação dos direitos de personalidade do homem- vida, liberdade de ir e vir - e dos direitos humanos tutelados pela Declaração Universal dos Direitos Humanos, além dos benefícios dados ao Direito do Trabalho. ${ }^{25}$ Logo, muito favorece ao combate ao trabalho escravo e ao tratamento dado ao mesmo, permitindo uma progressão jurídica a respeito e, consequentemente, reflexos na sociedade.

De acordo com o princípio da Irrenunciabilidade, o trabalhador não pode utilizar-se de qualquer argumento a fim de privar-se dos seus direitos. $^{26}$ Todavia, em momentos de crises políticas ou econômicas,

\footnotetext{
${ }^{22}$ RODRIGUEZ, Américo Pla. Princípios de Direito do Trabalho. 3 Edição, São Paulo-SP, Editora LTr.

${ }^{23}$ Idem.

${ }^{24}$ Citado na obra de Américo Pla Rodriguez, Princípios de Direito do Trabalho. 3 Edição, Sáo PauloSP, Editora Ltr

${ }^{25}$ RODRIGUEZ, Américo Pla. Princípios de Direito do Trabalho. 3 Edição, Sáo Paulo-SP, Editora LTr ${ }^{26}$ Idem.
} 
acompanhadas de altos índices de desemprego, o Princípio de Irrenunciabilidade encontra-se desacreditado e pouco utilizado. O número de pessoas capazes de renunciar a seus direitos em prol de estabilidade empregatícia tende a crescer ao passo que o desemprego aumenta levando, portanto, ao seu descumprimento e tendência a condições de labor deficitárias.

Por conseguinte, levando-se em consideração as características do princípio, para manutenção do mesmo é necessário que haja maior preocupação com a estrutura social, a fim de que a sociedade esteja apta a recebe-lo e preservá-lo, devendo haver um constante combate às consequências do desemprego, como o trabalho escravo, tão crescente em tempos de crise, para que, então, seja preservado o princípio.

Destarte, a intenção principal do capítulo foi demonstrar como os princípios se comportam mediante situações de escravidão contemporânea, a fim de que sua conservação- dos princípios- sirva de justificativa para $o$ combate à prática criminosa.

O capítulo 3 chama-se Escravidão Contemporânea, o qual buscou revelar os principais motivos de seu aumento em determinados períodos, partindo da sua conceituação e analisando jurisprudências que tratam a respeito, afim de identificar seu tratamento.

O conceito de Trabalho Escravo apresentado pelo Código Penal, embora apresente elementos que o completam, revela-se muito amplo para a aplicação ao caso concreto. Portanto, o vago conceito atinge não só as diversas situações reais de escravidão, como também causa dúvidas quanto à competência jurisdicional que deve julgá-las.

Por conseguinte, para que se delimite o conceito de Trabalho Escravo contemporâneo, deve-se levar em consideração que é exercido mediante violência ou fraude (coerção física ou moral), criando-se, na maioria dos casos, uma dívida artificial, impossível de ser quitada, não regulada pela legislação trabalhista, gerando consequências quanto à liberdade do escravizado.

Com as diversas buscas por uma evolução no sentido de delimitar a caracterização da escravidão moderna, juntamente à constante modernização da legislação trabalhista, os números de escravizados deveriam estar diminuindo gradativamente, ao passo que o combate às práticas escravocratas, por meio da ação do Ministério do Trabalho no ambiente rural, onde as práticas de trabalho escravo contemporâneo ocorrem com maior frequência, deveriam estar aumentando. Porém, 
gráficos e pesquisas recentes apresentam oscilações nos resultados, entre melhoras e pioras, de modo que evoluções significantes em determinado ano logo regridam no ano seguinte.

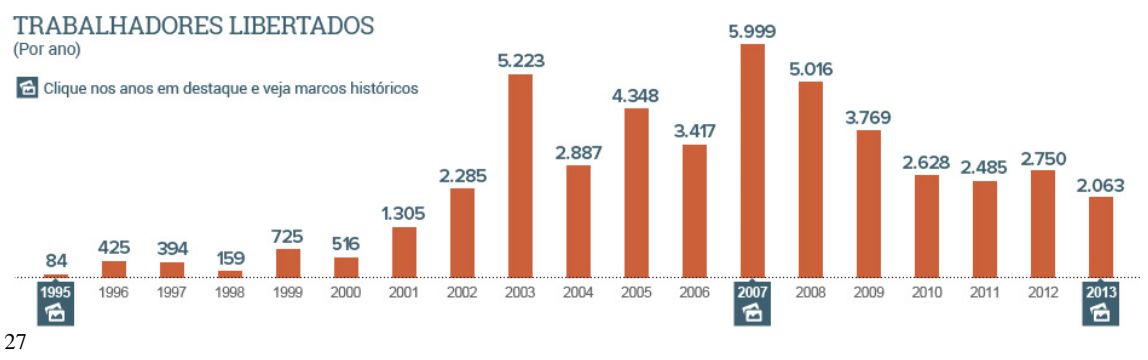

Primeiramente, foram estudados os fatores econômicos de tal realidade. Com o "milagre econômico" dos anos 70, inicia-se um processo de descentralização da indústria, o qual acarretou na instalação de indústrias em diversas partes da metrópole paulista e no seu interior. Esse processo levou a consequências, como no desenvolvimento do setor terciário, que juntamente à reestruturação industrial acarretou em grandes escalas de desemprego, causando a precarização das relações sociais e trabalhistas. ${ }^{28}$

Destarte, a desigualdade social se acentuou e os índices de desemprego também, levando o trabalhador de baixa renda à submissão a qualquer forma de trabalho. Logo, o primeiro fator econômico responsável pela incorporação e permanência da escravidão contemporânea no Estado de São Paulo foi a Globalização Neoliberal.

\footnotetext{
${ }^{27}$ Disponível em: http://g1.globo.com/economia Acesso em 13 AGO 2018

${ }^{28}$ LEME, Maria Cristina da Silva. Texto "O impacto da globalização em São Paulo e a precarização das condições de vida" Disponível em: http://www.scielo.cl Acesso em 11 DEZ. 2017
} 

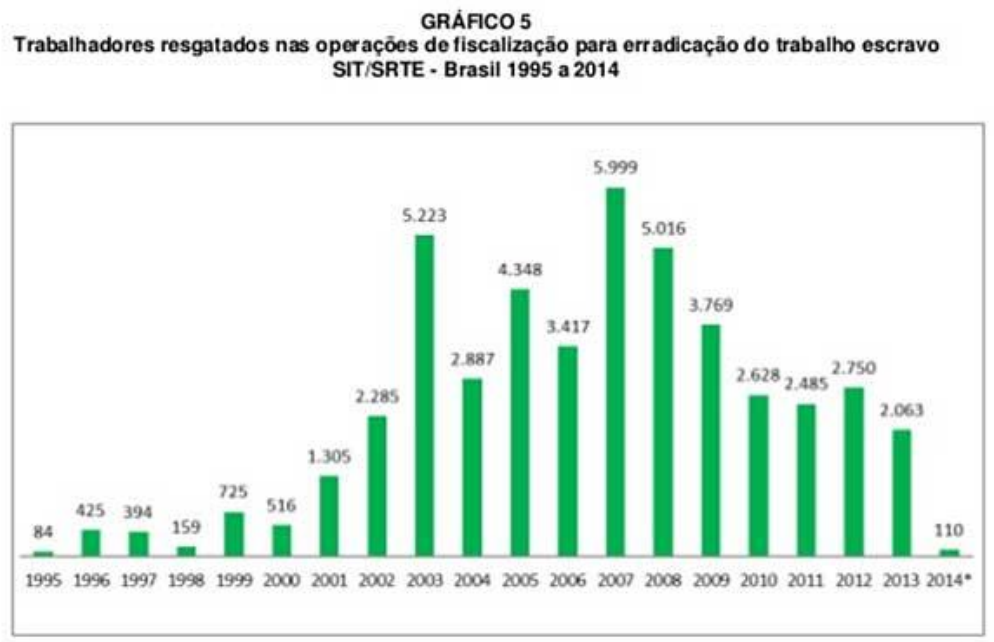

Fonte: MTE SIT/SRTE
Elaboraça: DIEESE. Subseçto Contag
Nota:'Aé maio

29

O gráfico a cima diz respeito ao número de escravos libertos entre 1995 e 2014. A quantidade de vítimas libertas corresponde ao número de pessoas que se submeteram a tal situação em troca de elementos básicos para sobrevivência, e também à força de determinados motivos que permitiram que a situação permanecesse. De acordo com o gráfico, o maior número de escravizados aconteceu em 2003, 2007 e 2008.

De acordo com o gráfico e com o contexto econômico do país nos períodos em que houve maior número de escravizados, as crises econômicas estão diretamente relacionadas à prática escravocrata, visto o maior índice de desemprego e, consequentemente, da maior quantidade de submissos a qualquer meio empregatício: a crise econômica de 2003 é responsável pelo número exorbitante de escravizados nesse período, visto às condições crescentes de desemprego. Quanto a 2007 e 2008, não há como deixar de colocar em evidência a crise sofrida pelos Estados Unidos, que refletiu em diversos países, dentre eles o Brasil.

Levando-se em consideração que a maioria das vítimas do trabalho escravo contemporâneo são nordestinas, e que a região apresenta alto índice de desigualdade social, em que a maioria da população sofre

\footnotetext{
${ }^{29}$ Disponível em: http://brasildebate.com.br Acesso em 14 MAR 2018
} 
com secas constantes, miséria e escassez de alimento, não há como não apontar a falta do Estado nessa região como um dos motivos da persistência da escravidão contemporânea no estado de São Paulo. Somado a tal fator, está a precária educação a que os jovens são submetidos. Esse despreparo educacional acarreta na falta de conhecimento sobre a realidade nacional e, consequentemente, na falta de informação à população, que migra da região ao estado de São Paulo na esperança de encontrar emprego e, consequentemente, caem em armadilhas. $^{30}$

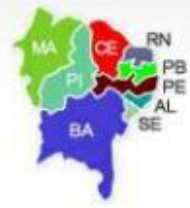

População: 53.081 .950 (2010)

População em idade escolar: 13.915.186 (2010)

PIB (R\$ 1.000,00): R\$ 397.502.594,00 (2008)

Renda Média (R\$): R\$ 396,00 (2009)
Taxa de

analfabetismo:

10 a 14 anos: $7.1 \%$

15 ou mais: $19,1 \%$

Fonte: IBGE

O Brasil, durante muitos anos, foi um país essencialmente agrário. Especializado na produção de diversos produtos, como a soja e o café, possuiu governantes de caráter exclusivamente agrário durante muitos anos, o que se caracterizou como República Velha. Mesmo que esse poder e influência tenha de dirimido com o passar do tempo, é inegável a influência que possui ainda hoje. Com relação ao estado de São Paulo, a produção cafeeira possui grande importância não só no setor agrário como também no industrial, visto que foi o responsável pelo desenvolvimento de São Paulo e pela sua transição de agrário para industrial.

Diante disso, não são poucos os casos de escravizados por fazendeiros, que utilizam dessa mão de obra com baixo nível de informação e estudos para aplicar a prática criminosa. ${ }^{32}$

\footnotetext{
${ }^{30}$ Disponível em: https://brasilbrasileiro1001.wordpress.com Acesso em 13 DEZ. 2017

${ }^{31}$ Disponível em: https://brasilbrasileiro 1001.wordpress.com Acesso em 10 MAI 2018

32 Texto: "O trabalho escravo rural contemporâneo no Brasil e a questão agrária" Disponível em: http://journals.openedition.org/espacoeconomia/804 Acesso em 4 JAN. 2018
} 
Por conseguinte, a escravidão contemporânea está intimamente ligada à questão agrária, por conta de as vítimas serem dirigidas ao trabalho rural.

Além desses gargalos principais à luta ao trabalho escravo contemporâneo, o estado de São Paulo enfrenta outro problema, tão principal quanto os outros, o qual o destaca quanto à pratica escravocrata: são as grandes empresas voltadas ao consumo, principalmente de confecção de roupas.

A maximização do lucro ocorre devido aos baixos preços das roupas que são colocadas no mercado, visto que há gastos insignificantes com a mão de obra, e também por conta da alta produção, já que trabalhadores são submetidos a longas jornadas de trabalho. Essa escravidão imposta pelo setor da moda é decorrência do alto índice de consumo de roupas não só no estado de São Paulo, como no país inteiro. Portanto, as empresas dessa área se veem atraídas a instalar filiais no país, principalmente na região com maior fluxo de consumo: Sudeste. ${ }^{33}$

Nesse sentido, expõe a jurisprudência do TRT da segunda região:

Tribunal Regional do Trabalho da $2^{\mathrm{a}}$ Região TRT-2 - RECURSO EX-OFFICIO E ORDINARIO : RECEXOFF 00018753920125020087 SP 00018753920125020087 A28. CONTRATO de facção. INVIABILIDADE DA DELINEAção DE FRAUDE NA AUSência de prova CABAL, NO MOMENTO DA AUTUAçÃO, da terceirização dE atividade finalística da contratante em prejuízo doS trabalhadorES EM CONDIÇÕES ANÁLOGAS ÀS DE ESCRAVO. INSUBSISTÊNCIA DOS AUTOS DE INFRAÇÃO. PROCEDÊNCIA. Inescapável a posição intervencionista do Estado ao se verificar que, apesar do aprofundamento da convivência na sociedade contemporânea impelir à revitalização de direitos fundamentais, a atividade humana em proveito de outrem persiste necessitando de significativa carga protetiva, por se vislumbrar, ainda hoje, resquícios de inaptidão para conferir a almejada dignidade, cabe avaliar, no caso concreto, se o denominado contrato de facção não se presta apenas à terceirização da mão-de-obra destinada à consecução de atividade precípua da contratante. Logo, a delineação do desvirtuamento da natureza de fornecimento de produtos acabados ostentada pelo pacto mercantil assim formalizado, com vistas à confecção de artigos de vestuário, depende, a partir da análise do objeto social daquela, da demonstração cabal de corresponder à prestação de serviços nos moldes repudiados na Súmula $\mathrm{n}^{\circ} 331$ do Colendo TST, em flagrante prejuízo aos integrantes das categorias profissionais

33 Texto: "Escravos da Moda: os bastidores nada bonitos da indústria fashion" Disponível em: http://revistagalileu.globo.com/Revista/ Acesso em: 4 JAN. 2018 
envolvidas, ainda que vislumbrada a hipótese de exploração do trabalho em níveis análogos aos dos escravos, situação lamentável que vem envolvendo grandes redes varejistas, mas que, isoladamente, a partir dos fatos presenciados no momento da inspeção, não é suficiente para concluir tratar-se de subterfúgio utilizado para mascarar o real liame jurídico.

\begin{abstract}
A jurisprudência a respeito trata de uma indústria de costura denunciada pela prática de escravidão contemporânea. Para que se enquadre em trabalho escravo, é preciso observar isoladamente se o caso concreto apresenta todos os elementos constantes fundamentais para caracterizar a prática criminosa, e é desse modo que as jurisprudências a respeito tratam casos concretos que envolvam acusação de escravidão: buscam o exato enquadramento entre a situação e a lei (tipicidade):
\end{abstract}

Ementa: TRABALHO ESCRAVO - DESCUMPRIMENTO DE NORMAS DE PROTEÇÃO AO PRESTADOR DE SERVIÇOS. O simples descumprimento de normas de proteção ao trabalho não é conducente a se concluir pela configuração do trabalho escravo, pressupondo este o cerceio à liberdade de ir e vir. Ementa: "Preliminar de nulidade da sentença. O pedido foi lastreado em instrumento coletivo que não foi juntado aos autos. No caso, a hipótese era de improcedência da ação e não de inépcia. Porém, isso não se pode dar porque é vedada a reformatio in pejus. Equiparação salarial. Não restaram comprovados os requisitos que ensejam o reconhecimento ao direito de diferenças salariais. Ausência do intervalo legal de 10 minutos. O reclamante durante sua jornada de trabalho, que era de 6 horas, usufruía 15 minutos de intervalo legal, não existindo prova do exercício da atividade contínua de digitador. Danos morais. O acessório segue a sorte do principal. O pedido foi amparado no pagamento de horas extras, que foram indeferidas. Ademais, alegar simplesmente que as horas extras não foram pagas, restando configurado o trabalho escravo, e que tal fato lhe trouxe prejuízo moral, sem qualquer prova do efetivo nexo causal, por si só, não comporta reparação por dano moral. Preliminar que se rejeita e Recurso Ordinário a que se nega provimento." 34

${ }^{34}$ TRT-2 - RECURSO ORDINÁRIO RO 169200600202005 SP 00169-2006-002-02-00-5 (TRT-2). Data de publicação: 19/06/2009 


\section{RAIO-X \\ QUEMÉ O TRABALHADOR ESCRAVO CONTEMPORÂNEO}

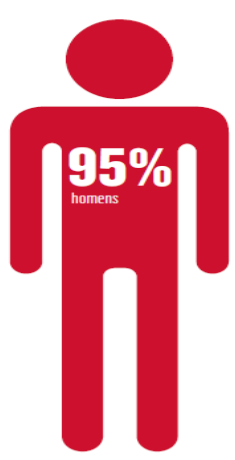

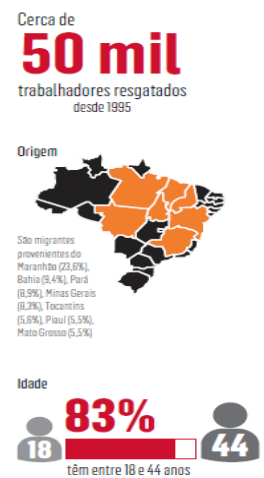

Trabalhadores libertados entre 2003 e 2014

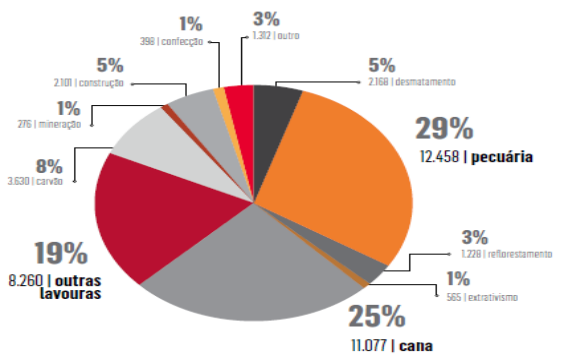

Escolaridade

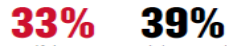

analfabetos só chegaram ate

Conforme acima, o setor da economia em que há maior incidência de trabalho escravo no Brasil é o de pecuária e cana de açúcar. Expõe a jurisprudência do TRF da quinta região, a respeito de uma fazenda de cana:

PENAL. CRIMES DE ALICIAMENTO DE TRABALHADORES E DE REDUÇÃO À CONDIÇÃO ANÁLOGA À DE ESCRAVO (ART.149, CPB). INDÍCIOS DE PROVAS INSUFICIENTES DA AUTORIA E MATERIALIDADE DELITIVA. ABSOLVIÇÃO DO ACUSADO. ART. 386, INCISO VI, SEGUNDA PARTE, E INCISO VII, DO CPP. APELAÇÃO PROVIDA. 1. Crime definido no art. 149, caput, do CPB - reduzir alguém à condição análoga à de escravo - quando já em vigor a Lei ${ }^{\circ} 10.803$, de 11/12/2003, o qual deu nova redação ao art. 149 do CPB. 2. O Ministério do Trabalho e Emprego, através de sua Delegacia Regional do Trabalho de Alagoas, procedeu a processo de fiscalização no período entre 01.11.2006 a 15.02.2007, nas Fazendas Prata, Mato Grosso e Lagoa Redonda, cuja atividade é exploração de cana de açúcar, com endereço à Fazenda Lagoa Redonda, situada na zona rural de Porto Calvo/AL, de propriedade e administração do denunciado, constatando uma série de procedimentos que contrariam a legislação trabalhista, os quais foram tidos como caracterizadores do crime de redução de trabalhadores à condição análoga à de escravo, tipificado no caput do art. 149 do CPB. Dito procedimento serviu também de elemento para a instauração da ação civil pública $\mathrm{n}^{\circ}$ 01276-2007-057-19-00-7, ajuizada na Vara Única do Trabalho de Porto Calvo-AL pelo Ministério Público do Trabalho da $19^{\mathrm{a}}$ Região. 3. O processo de fiscalização do Ministério do Trabalho registrou que no imóvel rural de propriedade do

\footnotetext{
${ }^{35}$ Disponível em: https://jornalggn.com.br/noticia Acesso em 3 FEV 2018
} 
denunciado, havia situações de trabalho em condições degradantes, destacando: a) não concessão regular de férias, bem como ausência de registro dos trabalhadores e de depósito do FGTS; b) desrespeito à convenção coletiva de trabalho; c) transporte de trabalhadores em veículos inadequados; d) ausência de instalações sanitárias e locais para refeições nas frentes de trabalho; e) não fornecimento de equipamentos de proteção individual, assim como ausência de funcionamento da Comissão Interna de Prevenção de Acidentes do Trabalho Rural - CIPATR e do Serviço Especializado em Segurança e Saúde no Trabalho Rural - SESTR; f) não realização de exames médicos admissionais, tampouco exames periódicos anuais; g) disponibilização de alojamentos em péssimas condições de higiene e sem instalações adequadas para repouso e preparo de alimentos; h) existência de armazéns dentro das fazendas, nos quais se praticavam preços superiores àqueles correntes no mercado. 4 . Das fotos constantes nos autos, dentre elas a do ônibus Santa Maria que transportava uma certa quantidade trabalhadores rurais, os quais tomam posição para fotografia, não se extrai uma super lotação de pessoa, que possa ofender a saúde física e mental daqueles trabalhadores. Tem uma outra foto que é a do caminhão de bóia fria, que também transporta trabalhadores rurais do imóvel de propriedade do denunciado, mas não se sabe que estes são empregados no acusado. 5. Se há transporte coletivo dos trabalhadores rurais daquela localidade fazendária rural, não há, consequentemente, cárcere privado, não havia impedimento de liberdade de locomoção dos trabalhadores, uma vez que as próprias fotos tiradas pelos fiscais do trabalho demonstram a liberdade de locomoção daqueles rurícolas. 6 . O conjunto probatório constante dos autos não é apto a demonstrar que os trabalhadores rurais encontrados no imóvel rural do denunciado estavam submetidos à condição análoga à de escravo, submetidos a quaisquer das formas descritas no artigo 149, do Código Penal. 7. Ausência de prova suficiente para subsidiar a imputação pelo delito do art. 149 do CPB. Alguns dados apontariam para a ocorrência de indícios, mas não de prova que autorize condenação, por sua própria indigência. 8. Ainda que se admita a imposição de um decreto condenatório com base em indícios, há necessidade de que estes indícios sejam veementes, convergentes e impregnados de elementos positivos de credibilidade. O que não é o caso dos autos. 9. Havendo dúvidas, merece prevalecer em favor do acusado, o princípio in dubio pro reo, com fulcro no art. 386, VI segunda parte e inciso VII, do Código de Processo Penal Brasileiro. 10. Apelação provida. Reforma da sentença. Ação penal improcedente. Absolvição do acusado EDGAR ANTUNES NETO da imputação que lhe é feito às penas do art. 149 do CPB, com fulcro no art. 386, inciso VI, segunda parte, e inciso VII, do Código de Processo Penal Brasileiro. (Origem: Tribunal Regional Federal - $5^{\text {a }}$ Região. Classe: Apelação Criminal - ACR7945/AL. Número do Processo: 200880000021494. Código do Documento: 281732. Data do Julgamento: 08/11/2011. Órgão Julgador: Segunda Turma) 


\section{CONCLUSÃO}

Embora a jurisprudência acima esteja no sentido de absolvição do réu, é inegável os elementos constantes presentes na decisão que também se enquadram em diversas situações de escravidão. Entretanto, devido à falta de cerceamento da liberdade, elementar importante para que se observasse a tipicidade, já exposta anteriormente, o réu obteve absolvição com base no princípio do in dubio pro reo.

Logo, fica evidente que a força da lei, embora deva ser encarada como a cima de tudo e de todos, quando relacionada à prática de trabalho escravo é desrespeitada explicitamente, basta que fatores de ordem econômica, política e social- explicitados acima- interfiram na realidade. A jurisprudência a respeito busca respeitar as elementares presentes no artigo 149 do Código Penal, dando um tratamento cada vez mais coerente ao tema e próximo ao que o legislador busca proteger por meio da tipificação da escravidão contemporânea.

\section{REFERÊNCIAS BIBLIOGRÁFICAS}

LEME, Maria Cristina da Silva. Texto "O impacto da globalização em São Paulo e a precarização das condições de vida" Disponível em: http://www.scielo.cl Acesso em 11 DEZ. 2017

MARTINS, Sérgio Pinto. Direito do Trabalho. 33 Edição, São Paulo-SP, Editora Saraiva, 2017.

NASCIMENTO, Amauri Mascaro. Curso de Direito do Trabalho. 29 Edição, São Paulo-SP, Editora Saraiva, 2014.

RODRIGUEZ, Américo Pla. Princípios de Direito do Trabalho. 3 Edição, São Paulo-SP, Editora LTr.

SUSSEKIND, Arnaldo. VIANA, Segadas. MARANHÃO, Délio. Instituições do direito do trabalho. 15 Edição, São Paulo-SP, Editora LTr. 